This is a pre-print version of:

Semino, E., Demjén, Z., and Collins, L. C. (2020) Person-ness of voices in lived experience accounts of psychosis: Combining literary linguistics and clinical psychology, Medical Humanities.

\title{
Person-ness of voices in lived experience accounts of psychosis: Combining literary linguistics and clinical psychology
}

\begin{abstract}
In this paper, we use concepts and insights from the literary linguistic study of story-world characters to shed new light on the nature of voices as social agents in the context of livedexperience accounts of voice-hearing. We demonstrate a considerable overlap between approaches to voices as social agents in clinical psychology and the perception of characters in the linguistic study of fiction, but argue that the literary linguistic approach facilitates a much more nuanced account of the different degrees of person-ness voices might be perceived to possess. We propose a scalar Characterisation Model of Voices and demonstrate its explanatory potential by comparing two lived-experience descriptions of voices in interviews with voice-hearers in a psychosis intervention. The new insights into the phenomenology of voice-hearing achieved by applying the model are relevant to the understanding of voice-hearing as well as to therapeutic interventions.
\end{abstract}

\section{Introduction}

The topic of this paper is best introduced by quoting the people who will be the focus of our discussion: two individuals who hear voices that other people cannot hear (a phenomenon also known as Auditory Verbal Hallucinations). ${ }^{1}$ Both people were interviewed about their voice-hearing experiences between 2017 and 2019, while they were using Early Intervention in Psychosis services provided by the UK's National Health Service in the North East of England. ${ }^{2}$ As part of the interviewing process, these two individuals were given the pseudonyms 'Carl' and 'Orla'. In answer to the first interview question about how each person would describe the voices they have been hearing recently, Carl begins as follows:'i

Right, ehm, well I hear bangs in the walls. Ehm, and it's like, it taps, and it ends up getting louder and louder, but I can feel that, I can actually feel them tapping, like wherever it is I can feel it, and it gets worse and worse and worse. And when I go in public places and things like that, sometimes I can hear the voices basically change, so someone will be talking but then it isn't their voice that I can hear, I see someone else's voi ... it's someone else's voice that's there.

In answer to the same question, Orla replies:

Well I've been hearing a few voices recently but the main one's always been this one woman. Ehm, it's always nasty little thoughts or things she'll say or sometimes she'll just scream. Just scream end on end or I'll hear her whispering. 
For Carl and Orla, hearing voices is part of a range of problematic experiences that have led them to seek psychiatric help. For clinical psychologists, providing that help involves, amongst other things, understanding the precise nature of the voices that each person hears, and the relationships involved.

The proportion of the general population who hear voices that others cannot hear has been estimated to be as high as $10-20 \%{ }^{3}$ (but see de Leede-Smith and Barkus). ${ }^{4}$ More specifically, voice-hearing is experienced by $70 \%$ of people with diagnoses of schizophrenia, ${ }^{3}$ but is not necessarily associated with mental health problems. Some voice-hearers cope well with their voices, and in some cases voices are highly valued as evidence of a special sense or gift, as, for example, with spiritualists who engage in mediumship. A crucial dimension of variation is the degree of distress that is associated with voice-hearing. In turn, distress has been found to depend on the relationship between voice-hearer and voices, and the extent to which voice-hearers feel they can control their voices, or feel controlled by them. ${ }^{5,6}$

Alongside Carl and Orla, 38 other voice-hearers who had been accessing the same mental health service for psychosis for nine months or less took part in semi-structured interviews, as part of the Wellcome-funded 'Hearing the Voice' project at the University of Durham, UK. ï Interview questions related to: the terms that participants would use to describe their experiences; the qualities and content of the voice-hearing experience; the voices as having their own character or personality; the onset of voice-hearing; changes in the experience over time; and participants' beliefs about/understanding of the experience. The interviews were transcribed and then coded by the 'Hearing the Voice' team for a number of clinically relevant phenomena. These phenomena included, among other things, whether each participant's description of their voices involved 'minimal' or 'complex' personification, as we explain in more detail below. Carl's interview was classified as an example of 'minimal' personification, and Orla's of 'complex' personification. This classification is linked to the recent understanding in clinical psychology that the degree to which voices are experienced as individuated social actors by the voice-hearers has consequences for what kinds of interventions might be appropriate and how well people are likely to cope with these experiences (see discussion below).

In this paper, we argue that the study and classification of voices in clinical psychology bears many parallels with the study and classification of fictional characters in 'cognitive poetics' or 'cognitive stylistics' - a field that lies at the interface between linguistics, literary studies and cognitive science. ${ }^{7,8,9}$ More importantly, we show that characterisation frameworks from cognitive stylistics/poetics can make a novel contribution to the study of degrees of personification in first-person accounts of voice-hearing, particularly thanks to their linguistic focus. ${ }^{10,11}$ In turn, this is potentially relevant to therapeutic interventions that rely on an in-depth understanding of each person's voice to attempt to change the relationship between voice-hearer and voices in beneficial ways. ${ }^{12}$ We demonstrate our argument with reference to a detailed analysis that we conducted on Carl and Orla's interviews specifically and summarise our approach in what we call the Characterisation Model of Voices. ${ }^{\text {iii }}$

Before we proceed, two caveats are in order. First, the fact that Carl and Orla differ both in terms of their gender and in terms of the degree of personification of their voices is not 
meant to suggest that the two differences are related. Second, the fact that we are drawing parallels between the study of voice-hearing and the study of fictional characterisation should by no means be taken to suggest that we are dismissive of the reality of voicehearing experiences. On the contrary, the approaches we combine in this paperpsychological approaches to voice-hearing and cognitive stylistic/poetic approaches to characterisation - have in common the fact that they take the individuals involved very seriously: voice-hearers and the voices they hear; and readers and the characters they imagine while reading narrative texts.

In the rest of the paper, we discuss the following areas: the status of voices and characters; the classification of voices and characters; and the linguistic analysis of descriptions of voices and characters. In the concluding section, we summarise the contribution that a literary linguistic approach to characterisation can make to the study of voice hearing by outlining a language-based scalar model of the personification of voices.

\section{The status of characters and voices}

The ontological status of characters is a well-known source of debate in the study of fiction. Eder et al. (p. 8) ${ }^{13}$ summarise this debate by distinguishing four main types of views regarding the ontology of character:

- Philosophical views according to which characters do not exist (e.g. Currie 1990); ${ }^{14}$

- Philosophical views according to which characters are 'abstract objects beyond material reality' (e.g. Thomasson 2003); ${ }^{15}$

- Semiotic theories according to which characters are 'signs or structures of fictional texts' (e.g. Branigan 1984); ${ }^{16}$

- Cognitive approaches according to which characters are 'representations of imaginary beings in the minds of the audience' (e.g. Culpeper 2001). ${ }^{17}$

The cognitive stylistics/poetics tradition tends to adopt the last-listed cognitive view. This is because, as Culpeper and Fernandez-Quintanilla put it, it is 'the only position that accommodates an audience' (Culpeper and Fernandez-Quintanilla, p. 94). ${ }^{11}$ Stockwell and Mahlberg similarly appeal to the experience of readers when they argue that the process of characterisation is central to the reading of literature: 'Of course, the relationship that readers develop with fictional characters is a main motivating factor in reading literature at all' (Stockwell and Mahlberg, p.130). ${ }^{10}$ From this general perspective, characters are imagined by readers to be similar to 'real' human beings unless there is evidence to the contrary, ${ }^{17,18}$ as well as potentially having additional characteristics associated with genre (e.g., to use an example from film, the hero in a Western movie is unlikely to die; Culpeper and Fernandez-Quintanilla, p. 102). ${ }^{11}$ Readers' reliance on their experience of people in the 'real' world to make sense of characters in fiction applies, among other things, to 'mind attribution' or 'mind modelling', i.e. the process of attributing beliefs, intentions and emotions to characters. ${ }^{19,20,21}$ This is in turn important for understanding and enjoying fictional worlds and plots.

A recent development in the cognitive psychological and philosophical study of voice hearing similarly raises questions about the status of 'voices' by appealing to the way in 
which voice-hearers experience them. Bell 2013 and Wilkinson and Bell 2016 criticise the tendency in the clinical psychological literature to treat voices primarily as 'hallucinated words or sounds' (Bell p. 1) when trying to explain their origin. ${ }^{22,23}$ This, Bell argues, ignores the fact that voice-hearers' descriptions of their voices suggest that they are experienced as 'hallucinated social identities' or 'internalised social actors', in spite of the fact that they 'stem from an internal source' (Bell, p. 1). ${ }^{22}$ More specifically, voices are described as producing 'coherent communicative speech acts' (Bell, p. 1);22 they are endowed with attitudes and intentions; they may be attributed different kinds of identities, including, in some cases, proper names; and they may be involved in the kinds of interactions that are typical of social relationships in external interpersonal social contexts (see also Hayward 2011, Hayward 2015). ${ }^{24,} 25$ There is a clear parallel here with the cognitive stylistic approach to characterisation we have outlined above.

For example, Carl describes his voices as a cohesive group that has a shared stance and gangs up on him:

They're all, they're all on each other's side kind of thing. They're all against me!

And, in response to an interview question, Orla says that she and her main voice 'talk back' at each other, and adds:

Just like in a conversation like this, she'll just do that

From this perspective, hallucinatory sounds or words are a consequence, rather than the cause, of the perception of voices as social actors. This helps to explain why some people perceive presences and/or communication without an auditory component - something that is obscured by use of the term 'voice' itself. Orla, for example, repeatedly mentions sensing the presence of her main voice even in the absence of any auditory perception:

like in me sleep I can feel her like sit next to us in me bed

Crucially, Wilkinson and Bell point out that differences in the kinds of social actors and relationships experienced by voice-hearers are associated with different levels of distress. ${ }^{23}$ Their approach, therefore, has implications not just for the aetiology of voices, but also for therapeutic interventions, which have recently started to exploit the person-like characteristics of voices. ${ }^{12,24}$

\section{Typologies of characters and voices}

In this section, we begin by showing some key parallels between typologies of fictional characters and typologies of voices, including both binary distinctions and scalar accounts. We then combine insights from both traditions to the classification of Carl's and Orla's voices, and particularly demonstrate the contribution that insights from the study of characterisation can make to discussions of degrees and types of personification of voices. 


\subsection{Typologies of characters}

One of the most influential concepts in the study of fictional characters is Forster's distinction between 'flat' and 'round characters':

Flat characters were called "humours" in the seventeenth century, and are sometimes called types, and sometimes caricatures. In their purest form, they are constructed round a single idea or quality: when there is more than one factor in them, we get the beginning of the curve towards the round. (Forster, p. 67) ${ }^{26}$

The test of a round character is whether it is capable of surprising in a convincing way. (Forster, p. 78)26

Flat characters, according to Forster, 'can be expressed in a single sentence', as in the case of Proust's Princess of Parma, who is entirely characterised by the utterance: 'I must be particularly careful to be kind.' Protagonists, on the other hand, tend to be round characters, as in the case of 'Madame Bovary-who, like Moll Flanders, has her book to herself, and can expand and secrete unchecked' (Forster, p. 77). ${ }^{26}$

Culpeper restated Forster's distinction by drawing from social cognition. ${ }^{17}$ He claimed that flat characters are processed via 'category-based impressions', i.e. by instantiating an existing 'social schema' for a type of person, i.e. a bundle of generic knowledge and beliefs about a type of person. Round characters, on the other hand, are too complex and individualised to be understood solely as instantiation of existing schemata, and require 'person-based impressions', i.e. mental representations that are specific to that character. Culpeper stresses that these two concepts are best seen as opposite ends of a continuum, rather than clear-cut categories. This is also implicitly suggested by Forster's idea of 'the beginning of a curve towards the round' in the quotation above.

A scalar approach to the classification of characters is also proposed by Stockwell (see also Stockwell and Mahlberg). ${ }^{10,21}$ Stockwell argues that the degree of 'person-ness' attributed to characters is modelled on real-life perceptions of people and other entities as 'persons', i.e. as conscious beings with an individual identity, agency and minds of their own (Stockwell, p. 116). ${ }^{21}$ Stockwell points out that each of us is, for oneself, the best example of a person, followed by close friends and relatives, less familiar people, pets, other animals and, at the opposite end of the scale, inanimate objects and abstractions. In the same way, some fictional characters will be perceived as very high in person-like qualities - usually protagonists who are described at length and in detail, including in terms of their internal states. In Stockwell's terms, '[t]he reader's relationship with such a character would be close, direct, pacy and qualitatively rich' (Stockwell, p. 111). ${ }^{21}$ The other end of the personness scale is occupied by what Stockwell calls 'the poorest examples of people', i.e. 'landscape objects; immovable objects; human-scale objects such as tools; machines with moving or display parts; plants; animals; and groups or ill-defined people [...] (Stockwell, p. 111)..$^{21}$

Stockwell points out, however, that even the entities at the lowest end of the person-ness scale can be made more person-like via stylistic and narrative techniques such as the 
personification of abstractions (e.g. death as the Grim Reaper) and the anthropomorphisation of animals through the attribution of the ability to speak and think, as is typical of fairy tales. ${ }^{21}$ In other words, the way in which such entities are described and represented in language determines the degree of roundness or complexity of personification that audiences perceive. Our contention is that this central idea and its associated analytical categories from the literary linguistic approach to characterisation can usefully be transposed to the voice-hearing context.

\subsection{Typologies of voices}

As noted earlier, the degree of personification is also a key issue in clinical approaches to voice-hearing. In the analysis of the 40 interviews we introduced in section 1, Alderson-Day et al. make a binary distinction between 'minimal' and 'complex' personification, as follows:

Minimal personification: The voice has few person-like qualities; is attributed to a person or described as being "like a person" but without further elaboration. Personlike characteristics tend to remain stable over time and follow a single theme (e.g. the voice is "mean", or a "nasty man").

Complex personification: The voice is described as having more than one kind of person-like quality. These may include elaborate descriptions of intentional states (the voice wants/thinks/feels), agency (the voice will "make something happen"), or identity (the voice "comes" from somewhere or has a specific and idiosyncratic ontological status). Complexity is not a simple function of the frequency, quantity or topic of speech, but will typically involve a voice being attributed multiple, qualitatively different person-like qualities (e.g. voice has an identity and multiple mental states) which may vary over time. (Alderson-Day, p. 6) ${ }^{2}$

They identified some kind of personification in all interviews, but only $40 \%$ were classified as displaying complex personification (26 out of 40 ).

The opposition between minimal and complex personification bears considerable resemblance both to Forster's distinction between flat and round characters (and Culpeper's socio-cognitive re-statement of it) and to the opposite ends of Stockwell's person-ness scale. Minimal personification captures both lack of elaboration and the paucity of person-like qualities; while complex personification involves greater elaboration in terms of a wide range of person-like qualities.

Following Wilkinson and Bell, ${ }^{23}$ Alderson-Day et al. also employed in their coding a more detailed four-way classification of voices in terms of types of agency, which can be summarised as follows:

- Absent agency:

- Agency without individuation: clicks, bangs, horns, murmuring crowd communicative intent, not attributed to a specific person (e.g. the shouting of a specific word) 
- Internally individualised agency:

- Externally individualised agency: a specific agency, potentially identifiable by individual characteristics but without any nominative reference associated with specific identities from the 'outside world' (including non-corporeal individuals from popular culture or religion)..$^{23}$

These four categories arguably form a cline of person-ness similar to Stockwell's, but with a focus on the characteristics that are most relevant to voices, such as the nature of the sounds that are perceived. The category of 'Externally individualised agency', which captures those voices that are identified with external entities such as known individuals, is similar to the cases of characters in fictional works who correspond to real-world entities, such as Richard III in the eponymous play by Shakespeare, or Margaret Thatcher in the film The Iron Lady. ${ }^{11}$

\subsection{Combining typologies of voices and characters to Carl and Orla's accounts of voice- hearing}

We have already drawn some parallels between clinical approaches to personification in voice-hearing and literary linguistic approaches to characterisation from cognitive stylistics/poetics. In this section, we flesh out some of these parallels and begin to illustrate what the literary linguistic approach can add by applying the different categories to Carl and Orla's descriptions.

\section{Carl's voices}

As we mentioned earlier, Carl's answer to the first interview question ('if I could ask you to describe some of the voices or voice-like experiences you've been having recently?') begins as follows:

Right, ehm, well I hear bangs in the walls. Ehm, and it's like, it taps, and it ends up getting louder and louder, but I can feel that, I can actually feel them tapping, like wherever it is I can feel it, and it gets worse and worse and worse.

The opening reference to 'bangs in the wall' corresponds to Wilkinson and Bell's notion of 'absent agency' as it indicates the perception of noises (as opposed to meaningful sounds) and includes no reference to a source or agent. ${ }^{23}$ Carl then starts using the verb 'tap' with an agent as grammatical subject. However, this agent is either an indistinct plural group ('them') or a singular entity that is referred to via the inanimate pronoun 'it'. In other words, agency is not actually absent, but the agent or agents are undefined, and not explicitly described as human. Up to this point, the entities involved are therefore so low on Stockwell's person-ness scale as to not even qualify for what Forster would call a flat character.

Carl then adds that he sometimes hears the voices of 'real' people turn into 'someone else's voice' and continues as follows: 
Ehm, other times it will be just humiliating me, things like that, I'Il hear, I hear someone shout, 'gay boy' or something like that.

In Wilkinson and Bell's terms, this kind of experience is a case of 'Agency without individuation', ${ }^{23}$ as Carl describes speech acts and words addressed to him by an unspecified agent. More precisely, this agent still seems to oscillate on the boundary between personness and lack of it: the inanimate pronoun 'it' is used as the grammatical subject of the verb 'humiliate', but, immediately after, the animate pronoun 'someone' is used as the subject of 'shout', which is then followed by a direct speech report of what, in context, counts as an insult: 'gay boy' (see section 4 for more detail).

Carl is one of the least talkative interviewees in our data, and provides very little further detail in answer to subsequent questions. However, he does clarify that he mostly hears a voice that he describes as 'the main one'. When explicitly asked to describe that voice 'in terms of how it sounds', he replies as follows:

Carl: Eh ... just like an angry man.

Interviewer: Ah ah. Is he kind of old or young or ...?

Carl: A bit old.

Here the voice is given a gender ('man'), an emotional attitude ('angry'), and, following a further prompt from the interviewer, a tentative age group ('a bit old'). In answer to further questions, Carl adds that the voice does not 'have an accent really' and does not sound like anyone he knows except for reminding him of his friends 'when they take the mick'.

Overall, Carl's main voice is person-like and qualifies for Wilkinson and Bell's notion of 'Internally individualised agent'. ${ }^{23}$ However, this particular category actually allows for quite a wide range of variation, and Carl's voice is in fact only given a small number of fairly generic qualities (see 'primitive categories' in Culpeper, p. 76). ${ }^{17}$ Moreover, the only utterance that is ever attributed to this main voice throughout the interview is the one we have already mentioned, i.e. 'gay boy'. As such, in Forster's terms, this voice would be best described as a flat character, that is fully captured by a category-based impression involving the social schema, or stereotype, of an angry old man.

Even though, in the next section, we will point out a few further features of Carl's voices, the extracts we have discussed so far explain why, in Alderson-Day et al.'s binary classification, Carl was coded as a case of minimal personification. ${ }^{2}$

\section{Orla's voices}

Orla reports some recent experiences of hearing voices that are similar to Carl's main voice in being human but minimally characterised: 
Just recently, the past few weeks, I've been hearing like a child or a baby crying, like screeching crying. And then two drunk men talking. But I don't know where they've come from to be honest.

However, most of Orla's contribution to the interview is devoted to the description of her main voice - 'this one woman' whom Orla calls 'May' and explicitly describes as 'a bully'. As we mentioned earlier, this 'voice' can be seen and felt as a presence even in the absence of any auditory perception:

I can see her standing in the room ... like I could feel her presence ...

When asked whether the voice reminds her of anyone, Orla says that the voice occasionally repeats words that Orla's father 'used to say'. However, the voice is not identified as anyone from Orla's external world. As such, like Carl's main voice, this voice also falls within Wilkinson and Bell's Internally individualised agency, ${ }^{23}$ but is a rather different example of this broad category.

We have already mentioned how Orla describes herself and her voice talking back to each other. In the next section, we show in more detail how Orla's voice is attributed a variety of tones of voice, topics and mind states. Here we focus on a crucial aspect of Forster's definition of round characters, which is also emphasized in Culpeper's notion of personbased impressions, namely change and the ability to surprise. ${ }^{17}$

Change over time is not explicitly included in in Wilkinson and Bell's typology, ${ }^{23}$ but it was one of the codes that Alderson-Day et al. applied to the interviews, and a possible feature of complex personification. In the interviews, participants were asked about the onset of their voice-hearing experiences and given a chance to make a comparison with the present. Orla explains that she has been hearing her main voice since she was six, and adds that, at the time: 'she was just copying, taking the mick out of me a little bit when I was little', so that she saw the experience as an 'imaginary friend type of thing'. However, when Orla reached adolescence, the voice started to 'get on about me weight a lot', or to talk about Orla's father, whom Orla describes as an alcoholic. We will return in the next section to the ways in which different aspects of Orla's 'face' are attacked by her main voice.

In addition to changing over time, Orla's voice is described as relatively unpredictable at the present time. In response to a question about tone of voice, Orla says:

It's not always the same, it's like sometimes it's just low, like a low tone and it's like you know, like an everyday type of voice. And then sometimes it's screeching and sometimes it's like full-on shouting. And it's, she just changes, depending on her mood.

Similarly, the voice can be critical of Orla, and sometimes abusive, but not always:

Or she tells us to die, she does that a lot. But otherwise it's just be like everyday chat. 
However, the occasions when the voice is not critical or abusive make Orla suspicious:

I don't know, sometimes she can be OK and seem like a nice person. But then it almost/always feels like there's another motive underneath it.

Here the description of the voice as 'a nice person' is hedged by 'seem', and the reference to 'another motive' suggests a contrast between appearance and reality as far as the true nature of Orla's voice is concerned.

Overall, even though both Carl's and Orla's main voices are instances of Wilkinson and Bell's Internally Individuated Agency, ${ }^{23}$ they contrast with respect to their degree of person-ness and roundness/complexity. Orla's voice has a wider range of person-like qualities: gender; a name; a clear physical presence; and different tones of voice, moods and behaviours. These aspects account for why Orla's interview was classified as an instance of complex personification by Alderson-Day et al.. ${ }^{2}$ In addition, the criterion of having the potential to surprise from characterisation theory reveals a further aspect of person-like complexity in Orla's voice. The voice has not just changed over time, as Orla has developed from a child to an adult, but is also not entirely predictable in its current, ongoing attitudes and approach to communication. This is an additional person-like quality, as 'real' people can often be perceived to be unpredictable and not entirely trustworthy, but it also makes Orla's voice hard to categorise by Orla herself. While it could not be expected that the voices described by participants in the interviews could reach the complexity of some fictional characters (e.g. a novel's protagonist), overall, Orla's voice can be described as a round character in Forster's terms, or, in Culpeper's terms, as requiring a person-based impression.

Throughout this section, we have started to focus on specific linguistic aspects of Carl's and Orla's accounts of their voices as the basis of the description and classification of those voices. This is an area where the approach to characterisation developed within cognitive stylistics/poetics can make the most valuable contribution to the study of reports of voicehearing experiences.

\section{Analysing linguistic descriptions of characters and voices}

The approaches to the classification of voices from the psychological literature are based on first-person accounts from voice-hearers, and include some language-based criteria for each category. For example, Alderson-Day et al.'s definition of Minimal Personification includes cases where a voice is described as 'like a person' (e.g. Carl's 'just like an angry man'), but without further elaboration. And the definition of Complex Personification mentions descriptions of 'intentional states', 'agency' or 'identity', and includes some possible linguistic realisations of such descriptions, such as 'the voice wants/thinks/feels', for intentional states (Alderson-Day, p.9). ${ }^{2}$ Some concepts and distinctions in clinical psychology also involve an analysis of what the voices sound like (e.g. Do they sound like the voicehearer themselves? Do they have a regional accent?) and what speech acts they perform, as in the case of 'commanding voices', which tell the voice-hearer what to do. However, these categories and criteria are neither designed bottom-up to account for the range of things that voice-hearers might say, nor do they cover the full range of social schemata that may 
apply top-down. In addition, while some of the criteria are language-based, they are not systematically operationalised in terms of their different possible linguistic realisations. As we have already started to show, this backgrounds potential similarities between cases of minimal and complex personification, obscuring the likely continuum between these extremes.

In the study of characterisation in cognitive stylistics/poetics on the other hand, characters are seen as imaginary entities that arise 'in the interaction between top-down knowledge from the reader/perceiver's head and bottom-up information from the text' (Culpeper and Fernandez-Quintanilla, p. 93). ${ }^{11}$ The top-down aspect of characterisation is accounted for by drawing from cognitive psychology and social cognition, as in the case of the notion of social schema and the contrast between category-based and person-based impressions we mentioned earlier. The bottom-up analysis of characterisation, on the other hand, draws eclectically from different areas of linguistics, narratology and stylistics, and provides a sophisticated account of the variety of linguistic cues and patterns that contribute to the construction of characters. This is where characterisation frameworks can make a particularly novel contribution to the study of voices as social agents, and to the understanding of voice-hearing more generally, as we have already suggested.

In what follows, we systematically go through different groups of linguistic cues for characterisation, illustrating how these manifest in and shed further light on the differences and similarities between Carl's and Orla's voices in terms of person-ness and social agency.

\subsection{Explicit vs. implicit cues}

The interview questions we summarised earlier elicit both 'explicit' or 'direct' characterisation cues and 'implicit' or 'indirect' ones, in the terms used in the study of characterisation. ${ }^{11,13,17}$ 'Explicit' characterisation captures the explicit attribution of traits to characters, or, in our case, voices, such as when Carl describes his main voice as 'like an angry man', and Orla describes her voice as 'a bully'. We have already discussed the different ways in which the two participants directly describe their voices in section 3 . In that section, we also pointed out how Orla sometimes hedges her explicit attribution of traits to her voice ('sometimes she can [...] seem like a nice person'), suggesting that she feels she cannot always trust the impressions she receives.

Implicit characterisation captures all the different ways in which the utterances, attitudes and actions attributed to characters can lead to inferences about their traits and personalities. Characterisation frameworks, as outlined by Culpeper and FernandezQuintanilla, ${ }^{11}$ include a range of types of implicit characterisation cues, depending on the genre and text under analysis (see also Stockwell and Mahlberg's 'text-driven' approach to mind-modelling). ${ }^{10}$ For understanding the person-ness of voices as manifest in clinical interviews, the most relevant sources of implicit characterisation cues are:

- References to mental states and processes; and

- Verbal/communicative behaviour.

We will now consider each of these areas in turn. 


\subsection{References to mental states and processes}

In the study of fiction, references to characters' mental states and processes (including sensations, cognition and emotions) are considered in relation to mode of narration, thought presentation and point of view. ${ }^{27,28}$ Whether and how characters' internal states are presented distinguishes between, for example, third-person omniscient narrators (who have, in principle, privileged access to all characters' minds) and first-person narrators (who only have direct access to their own minds, but can attempt to infer the mental states of other characters). In both cases, references to internal states through mental process verbs such as 'think' or 'know' are characteristic of what Fowler calls 'Internal Psychological Point of View', ${ }^{28}$ i.e. the presentation of a fictional world through the mind of one or more characters. The description of a character's internal states directly contributes to our perceptions of that character (subject to the reliability of the narrator) and, other things being equal, pushes that character up Stockwell's person-ness scale. ${ }^{21}$ However, when references to internal states are accompanied by 'words of estrangement' (e.g. 'seem', 'apparently', 'perhaps'), we have a variant of what Fowler calls 'External Psychological Point of View' that emphasizes the inaccessibility of characters' minds (Fowler, p. 142). ${ }^{28}$

Both Carl and Orla use verbs referring to mental processes for their voices, but, consistent with what we noted before, Orla's attribution of internal states to her main voice displays greater variety and complexity.

As we mentioned earlier, Carl attributes an emotional attitude to his main voice via the adjective 'angry'. In addition, he uses the verb of cognition 'know' with the voices as grammatical subject. When asked about his earliest voice-hearing experiences, he says:

Ehm, well sometimes I, I'd get that scared I couldn't go to sleep on a night or I couldn't move, l'd be just sat there, scared to move, because as soon as I'd move, they'd know I was, I was ... I was there kind of thing.

Even though, overall, Carl's characterisation of his voices is relatively minimal, the attribution of cognitive states conveys a sense of their power and menacing motivation, which increases their person-ness. In addition, Carl explains the voices' ability to affect him as follows:

And it, because it, because ... because it's me, they know what to say, do you know, to annoy me...

Here Carl makes clear that he understands the voices as originating from himself ('because it's me'), which he then uses as an explanation for attributing to them the knowledge that is needed to have an effect on him through what they say ('to annoy me'). When asked directly by the interviewer if the voices know more than he does, he replies 'Just the same as stuff I know.'

Orla also attributes an angry attitude to her main voice, but does so by describing a (habitual) process, rather than a quality: 'she gets angry quick'. She also reports that the 
voices tell her 'about heaven and hell', 'where I'm going to go and all that' and 'what's going to happen the next day', and comments:

It's ... she's right most of the time

$[\ldots]$

So she just knows the future type of thing.

This attribution of eschatological knowledge lends Orla's voice authority and power, and, potentially, an additional supernatural element.

Finally, as we mentioned earlier, Orla states that her main voice changes depending on her 'mood', and that she [Orla] suspects a hidden 'motive' when her voice 'seem[s] like a nice person'. Another instance of this suspicion is expressed as follows:

she'll be sitting there going, now l'm here for you and all that kind of thing, it's like ... she's done nasty stuff in the past, why would I trust her type of thing? It could just be as like she's trying to manipulate us a little bit.

The expression 'trying to manipulate us' attributes to the voice a sophisticated intention and suggests a potential contrast between appearance and reality that creates a particularly heightened sense of person-ness. In addition, the use of expressions of uncertainty such as the modal verb 'It could just be' above and 'seem' in 'can [...] seem like a nice person' suggest Orla's awareness that she cannot access her voice's mind, in a way that is reminiscent of the 'estranged' variant of Fowler's External Psychological point of view we mentioned earlier. ${ }^{28}$

Overall, both Carl and Orla attribute minds to their voices, which contributes to their construction as rounded social agents. However, the power of Carl's voice comes from an overlap with his own mind, which means that they know how to affect him. In contrast, the power of Orla's voice comes from having a mind that is not just separate from Orla's, but also supernaturally knowledgeable and capable of deliberate dissimulation. This potentially suggests that Orla's main voices is more fully, three-dimensionally characterised, in a way that is independent from her own self.

\subsection{Verbal/communicative behaviour}

Linguistic approaches to drama and film have applied frameworks originally developed in Conversation Analysis and Pragmatics for the analysis of real-life interactions, to explain how we infer the traits and personalities of characters from the ways they speak, and particularly how they interact with one another. ${ }^{29}$ These approaches are also relevant to studying how verbal/interactional behaviour is reported in narratives such as novels, where the narrator uses different forms of speech presentation, e.g. by quoting directly or reporting indirectly, ${ }^{27,30}$ to represent the utterances attributed to characters. ${ }^{31}$ The firstperson accounts of voice-hearing that interview participants such as Carl and Orla provide in 
answer to interviewers' questions can be analysed in the same way as they also report in various ways what their voices say to them.

We have already pointed out some broad differences between Carl's and Orla's reports of the verbal behaviour of their voices. Orla repeatedly mentions interacting with her main voice: she says that she and her voice 'talk back' to each other, 'just like in a conversation'. In contrast, when asked whether he talks back to his voices, Carl says that he does not. More generally, Carl only uses 'say' as a speech-activity verb in relation to his voices, whereas Orla uses eight such verbs ('mumble', 'repeat', 'say', 'scream', 'speak', 'talk', 'tell', 'whisper'). While some voice-hearers use direct speech extensively to represent their voices' utterances, ${ }^{32,} 33$ Carl and Orla mainly use non-direct categories, and particularly Indirect Speech (e.g. Orla: 'she could tell us just to go hurt someone in public') and Narrator's Representations of Speech Acts (e.g. Carl's 'it will be just humiliating me'). ${ }^{27}$ These strategies themselves have implications for how vividly the voices are portrayed, or how life-like they seem.

However, here we will focus particularly on the implications of the content and style of the verbal behaviour attributed to Carl's and Orla's voices for the voice-hearer's 'face', which was classically defined by Goffmann as follows:

the positive social value a person effectively claims for himself [sic] by the line others assume he has taken during a particular contact. Face is an image of self delineated in terms of approved social attributes - albeit an image that others may share. (Goffman, p. 5) $)^{34}$

In other words, 'face' is a person's momentary sense of self or identity, which is based on their own communicative behavior and, importantly, their interlocutors' interpretations of and reactions to that behaviour.

\section{Facework, (im)politeness and characterisation}

The notion of face has been central to linguistic theories of 'politeness', ${ }^{35}$ 'impoliteness', ${ }^{36}$ and 'rapport management' in interaction. ${ }^{37}$ In brief, 'politeness' as a technical term is slightly different from, though not unrelated to, the everyday meaning of the word. It captures the linguistic ways in which we enhance other people's 'face' or sense of self (e.g. via compliments) or maintain others' sense of self while saying things that are potentially 'face-threatening' (e.g. by expressing a request in the form of a question rather than in the form of a command, as in 'Can you pass the salt?' vs. 'Pass the salt.'). ${ }^{35}$ Spencer-Oatey captures these phenomena through the terms 'Rapport enhancement orientation' and 'Rapport maintenance orientation' respectively. ${ }^{37,38,39}$ 'Impoliteness', on the other hand, captures the linguistic ways in which we might attack other people through insults, putdowns and threats - what Spencer-Oatey calls 'Rapport Challenge Orientation' ${ }^{36,37}$ These analytical frameworks have been employed in the linguistic study of literature to explain how we make inferences about characters from the ways in which they manage or orient to the face of other characters. ${ }^{40,41}$ In the absence of discounting factors, some face-related linguistic behaviours are taken to reflect stable character traits. ${ }^{17,42}$ 
Face itself can be broken down into different parts. Both Carl and Orla describe their voices as attacking the aspect of face that Spencer-Oatey 2002 calls Individual Identity Face - 'a fundamental desire for people to evaluate us positively in terms of our personal qualities; e.g. our competence, abilities, appearance etc.' (Spencer-Oatey, p. 540). ${ }^{37}$

As we showed earlier, Carl describes his voices as 'trying to embarrass' him and 'humiliating' him, particularly by shouting 'gay boy', an insult (as perceived by Carl) that Carl reports three times. These attacks on his Individual Identity Face implicitly attribute to the voices aggressive, abusive and homophobic characteristics, and explain Carl's summing up of the situation as 'They're all against me'.

Orla's voices are also described as attacking some aspects of her Individual Identity Face, and specifically her weight and physical appearance (something that she describes as starting when she reached adolescence):

just like pick on me weight, call us fat, call us ugly and that kind of thing.

In addition, Orla's voice at times orders her to do things. This threatens what Spencer-Oatey describes as Sociality Rights, ${ }^{39}$ which include 'equity rights' (being treated fairly, not being imposed upon, or exploited) and 'association rights' (being entitled to involvement and association with others). ${ }^{\text {iv }}$

In answer to a question about whether her voice-hearing experiences disrupt her life, Orla replies:

It means I don't want to go to work or go out ... It's like I sit at work and I won't speak to a single one of them. Just because May tells me not to, because they're a traitor, you know what I mean?

Here the voice's injunction 'not to' speak with colleagues 'because they're a traitor' challenges Orla's 'association rights' and restricts her social networks.

At other times, Orla is told by the voice to cause harm to others or herself:

And then she could tell us just to go hurt someone in public.<smiles>[C]1C=[C+]C=C1</smiles>

Or she tells us to die, she does that a lot.

Commands about harm to others challenge both Equity Rights and Association Rights, as they restrict Orla's freedom of action and cause her to perceive herself as a threat to the people around her, and hence potentially to withdraw from them. Such commands also have secondary implications for what Spencer-Oatey calls Relational Identity Face ('the selfconcept derived from connections and role relationships with significant others') (SpencerOatey, p.641), ${ }^{38}$ as Orla may end up seeing herself as a bad sibling, friend and colleague, especially when she hears herself say out loud what the voice says to her ('And then sometimes it comes out me mouth and I say it'). The commands about her own death have 
secondary implications for Orla's Individual Identity Face, as they suggest that Orla is not worthy of being alive.

Orla's voice performs different types of impoliteness, ${ }^{36}$ or, in Spencer Oatey's terms, engages in a wide variety of behaviours that have a Rapport Challenging Orientation. ${ }^{39}$ In this way, she behaves like a powerful participant in her interactions with Orla. Indeed, Orla explicitly says that, at times, 'It's like she can ... control what I do', and leads her to self harm. On the other hand, Orla's own attempts to control the voice through commands are unsuccessful: 'So if I tell her to go away, she wouldn't go away'.

In contrast, as we have mentioned, there are also occasions when Orla's voice seems to bolster her sense of self, or take a Rapport Enhancing Orientation:

So it's nice to have someone there at least that's like sitting there telling me, oh I'm on your side type of thing.

So it could be like, I kind of call out on a friend and she'll be sitting there going, now I'm here for you and all that kind of thing

In Spencer-Oatey's terms, ${ }^{39}$ here the voice arguably enhances Orla's Individual Identity Face, by expressing a positive attitude towards her, as well as her association rights, by expressing a commitment to her relationship with Orla. However, if this occurs when Orla is socialising with other people, it could also be argued that the voice creates an in-group (consisting of Orla and the voice) that contrasts with an out-group, consisting of everyone else. This therefore further threatens Orla's Association Rights with people in her life. As she puts it, 'A lot of my friends [...] they've kind of backed off, kept away from me a bit'.

Overall, this type of analysis reveals in detail the roundedness/complexity of Orla's voice as a social actor, particularly as compared with Carl's voice. The analysis reveals that Orla's voice alternates between undermining Orla's self-esteem and independence (Rapport Challenging Orientation, or impoliteness), and being friendly and supportive (Rapport Enhancing Orientation, which is a form of politeness). Even the latter cases, however, can have secondary Rapport Challenging implications, particularly with respect to Orla's relationship with external people in her life. Overall, this variety of interactional behaviours and potential motives explains Orla's explicit description of her voice as 'a bully', the fact that she says she cannot trust her, and the suspicion that the voice is manipulative (for a similar analysis of the interactional style of different voices see Demjén et al. ${ }^{33}$ ).

\section{Conclusion: characterising voices and voice-hearers}

This paper took as its point of departure the parallels between research on voices as social agents in the clinical psychology literature and studies of fictional characters in literary linguistics, particularly cognitive stylistics/poetics. These parallels concerned the ways in which voices and characters might be classified, particularly in terms of their complexity and person-like qualities, and the ways in which they are described through language. We then demonstrated the nuance that the literary linguistic account can add to discussions of the degree of person-ness that voices are attributed explicitly and implicitly. These nuances 
emerge directly from appreciating the full implications of how those voices are described by voice-hearers themselves.

Our analysis of Carl's and Orla's voices explains why they have been respectively classified as minimally and complexly personified by Alderson-Day et al., but also provides further evidence of both differences and similarities between the two voice-hearing experiences. Carl's voices, for example, are indeed minimal as compared with Orla, but they do still show some evidence of 'the beginning of the curve towards the round', in Forster's terms. ${ }^{26}$ In the case of Orla's main voice, on the other hand, we were able to explain the type of complexity involved; for example, the daily changing nature of it, and the range of different ways in which Orla's own self-esteem, freedom of action and association with others are challenged, more or less directly, by the voice's authority. Understanding these nuances and their implications is crucial because it can give us indications of which aspects of their experience and their relationship with the voices people might value, and which they might struggle with. This, in turn, is relevant to providing support in therapeutic interventions.

Alderson-Day et al. found that voices with complex personification were appreciated by voice-hearers for offering companionship and opportunities for conversation, even in the context of a generally negative evaluation. ${ }^{2}$ They suggest that this has implications for the increasing variety of new therapies that encourage personal relationships between voicehearers and their voices (Alderson-Day et al., p.7). The additional insights that can be gained by combining characterisation analysis with existing psychological approaches to voicehearing can make a contribution to refinements and further developments in therapeutic interventions that exploit the person-like qualities of voices. The linguistic account, for example, may point towards the particular aspect of complexity that is the source of distress, such as Orla's distrust of the voices' motivations and intentions. In other cases this might be linked more to how the voices exert power over voice-hearers in their utterances (see also Demjén et al. 2020). ${ }^{33}$ Such insights would be particularly relevant to therapeutic interventions that aim to reduce distress by helping voice-hearers change the ways in which they respond to their voices, such as 'Relating Therapy' and 'Avatar Therapy'. ${ }^{12}$

The kind of linguistic analysis that is associated with the study of characterisation in literary linguistics is also particularly well suited to demonstrating and unpicking the scalar nature of both the personification and the agency of voices. We pointed out, for example, how some descriptions fall between different categories in Wilkinson and Bell's model, such as between Absent Agency and Agency without individuation (e.g. 'it taps'), and between Agency without Individuation and Internally Individualised Agency (e.g. 'it will be just humiliating me'). ${ }^{23}$ We also demonstrated the extent of variation that can be found within the category of Internally Individualised Agency when paying close attention to the language voice-hearers actually use. In this way, our linguistic approach can be used to feed into discussions of the so-called 'psychosis continuum' ${ }^{43}$ As Collins et al. (under review) discuss, in linguistic terms, there are potentially multiple continua at play capturing different aspects of the psychosis experience. ${ }^{44}$ The degrees of personification and agency of voices can be seen as one such aspect.

The linguistic characteristics we discussed in the paper can be broadly captured in the scalar model of minimal-to-complex personification summarised in Table 1: the Characterisation 
Model of Voices. While some of the categories and features overlap, this model can serve as a guide to the range of ways in which voice hearers might describe their voices, and the range of features researchers and therapists might pick up on and interrogate. Not all features will be apparent or indicative in all descriptions, but the range presented here can hopefully provide a tangible means of making the most of voice-hearers' lived experience accounts, for the purposes of understanding and therapeutic interventions. 


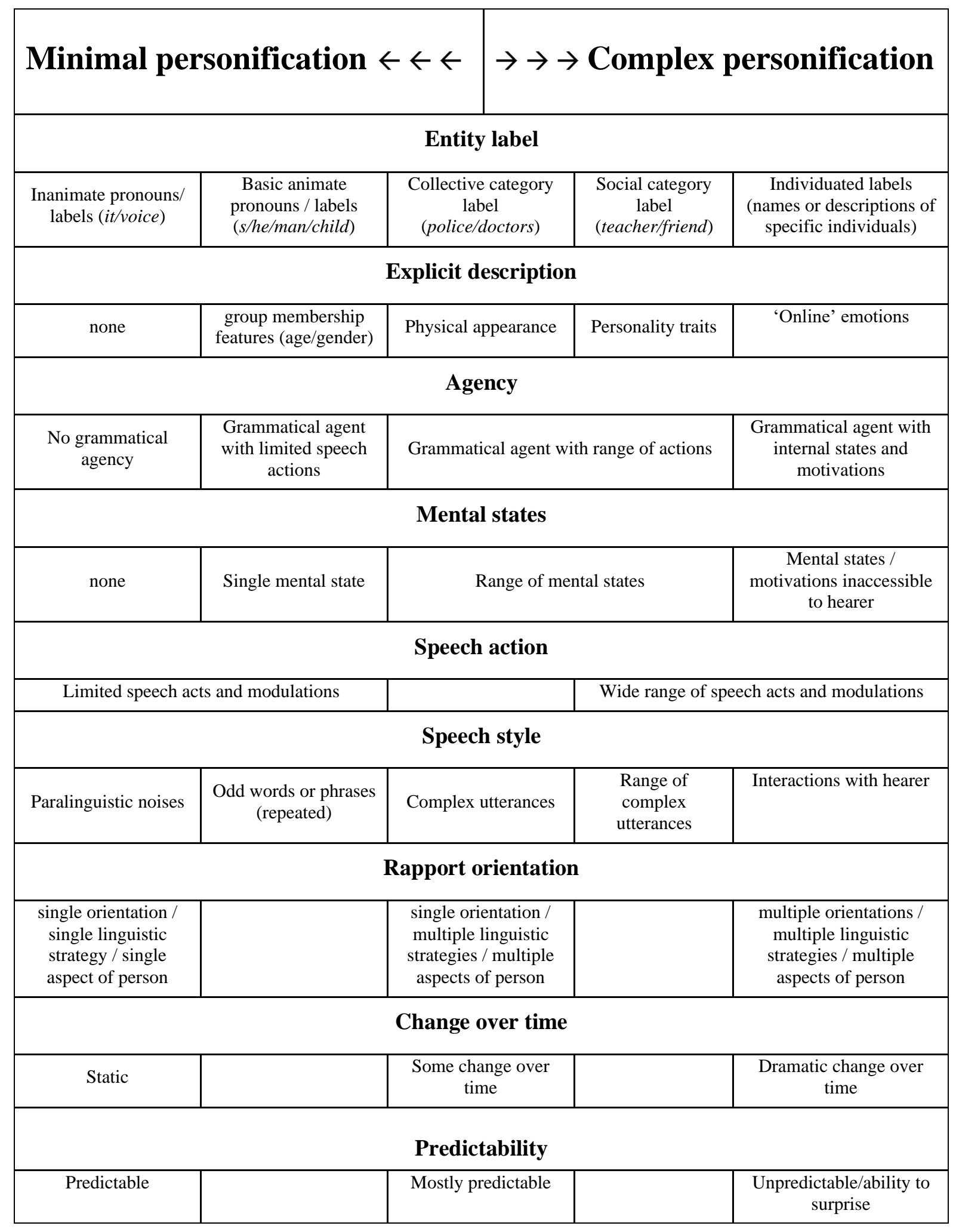

Table 1 - The Characterisation Model of Voices: linguistic dimensions of a scalar model of personification of voices. 


\section{Notes}

i. When quoting from the interview transcripts, we only include the interviewer's contributions as part of a quote when they amount to more than back-channelling feedback such as 'ah ah' or 'yeah'.

ii. Individuals with lived experience of voice-hearing were involved in the design and analysis stages of this project at the University of Durham.

iii. Carl and Orla's interviews were part of a set of nine interviews that were shared with the current authors by the Durham team while data collection was still going on, to exemplify different degrees of complexity in personification. These two specific interviews were then selected for analysis by the current authors for the following reasons: (a) they were coded by the Durham team as belonging to different personification categories (minimal vs. complex); (b) each interview involves descriptions of one 'main' voice (as opposed to several different voices with a similar status for the voice hearer); and (c) they do not differ dramatically in length, in contrast with other possible pairs of minimal/complex interviews (as interviews that were coded as involving complex personification tend to be longer than those coded as minimal).

iv. In contrast to Brown and Levinson, Spencer-Oatey does not consider this to be an aspect of 'face', but it clearly has implications for people's sense of self. ${ }^{39}$

\section{Bibliography}

1. Woods A, Jones N, Bernini M, Callrd F, Alderson-Day B, Badcock JC, Bell V, Cook CCH, Csordas T, Humpston C, Krueger J, Larøi F, McCarthy-Jones S, Moseley P, Powell H, Raballo A, Smailes D, Fernyhough C. Interdisciplinary approaches to the phenomenology of auditory verbal hallucinations. Schizophr Bull 2014;40(Suppl 4):S246-54.

2. Alderson-Day B, Woods A, Moseley P, Common S, Deamer F, Dodgson G, Fernyhough C. Voice-hearing and personification: Characterizing social qualities of auditory verbal hallucinations in early psychosis. Schizophr Bull 2020;sbaa095:1-9.

3. Upthegrove R, Broome MR, Caldwell K, Ives J, Oyebode F, Wood SJ. Understanding auditory verbal hallucinations: a systematic review of current evidence. Acta Psychiatrica Scandinavica 2016;133:352-67.

4. de Leede-Smith SE, Ebarkus E. A Comprehensive Review of Auditory Verbal Hallucinations: Lifetime Prevalence, Correlates and Mechanisms in Healthy and Clinical Individuals. Frontiers in Human Neuroscience 2013;7: 367.

5. Mawson A, Cohen K, Berry K. Reviewing evidence for the cognitive model of auditory hallucinations: The relationship between cognitive voice appraisals and distress during psychosis. Clinical Psychology Review 2010;30(2):248-58.

6. Varese F, Tai SJ, Pearson L, Mansell W. Thematic associations between personal goals and 
clinical and non-clinical voices (auditory verbal hallucinations). Psychosis 2016;8(1):12-22.

7. Semino E, Culpeper J, Eds. Cognitive stylistics language and cognition in text analysis. Amsterdam: John Benjamins, 2002.

8. Stockwell P. Cognitive poetics: An introduction. London: Routledge, 2002.

9. Stockwell P. Cognitive poetics: An introduction. Second Edition. London: Routledge, 2020.

10. Stockwell P, Mahlberg M. Mind-modelling with corpus stylistics in David Copperfield. Language and Literature 2015;24(2):129-47.

11. Culpeper J, Fernandez Quintanilla C. Fictional characterisation. In: Locher MA, Jucker AH, Eds. Pragmatics of Fiction (Handbooks of Pragmatics Vol. 12). Berlin: de Gruyter, 2017:93128.

12. Craig TK, Rus-Calafell M, Ward T, Leff JP, Huckvale M, Howarth E, Emsley R, Garety PA. AVATAR therapy for auditory verbal hallucinations in people with psychosis: a single-blind, randomised controlled trial. Lancet Psychiatry 2018 Jan 1;5(1):31-40.

13. Eder J, Jannidis F, Schneider R. Characters in fictional worlds. In: Eder J, Jannidis F, Schneider R, Eds. Characters in Fictional Worlds: Understanding Imaginary Beings in Literature, Film, and Other Media. Berlin: de Gruyter, 2010:1-66.

14. Currie G. The Nature of Fiction. Cambridge: Cambridge University Press, 1990.

15. Thomasson AL. Speaking of fictional characters. Dialectica 2003;57(2):207-27.

16. Branigan E. Point of View in the Cinema: A Theory of Narrativity and Subjectivity. Berlin: de Gruyter, 1983.

17. Culpeper J. Language and Characterisation in Plays and Other Texts. London: Longman, 2001.

18. Emmott C. Narrative Comprehension: A Discourse Perspective. Oxford: Clarendon Press, 1997.

19. Palmer A. Fictional minds (Frontiers of narrative). Lincoln: University of Nebraska Press, 2004.

20. Zunshine L. Why we read fiction: Theory of mind and the novel (Theory and interpretation of narrative). Columbus, Ohio: Ohio State University Press, 2006.

21. Stockwell P. Texture: A Cognitive Aesthetics of Reading. Edinburgh: Edinburgh University Press, 2009.

22. Bell V. A Community of One: Social Cognition and Auditory Verbal Hallucinations. PLoS Biol 2013;11(12): E1001723. 
23. Wilkinson S, Bell V. The Representation of Agents in Auditory Verbal Hallucinations. Mind \& Language 2016;31(1):104-26.

24. Hayward M, Berry K, Ashton A. Applying interpersonal theories to the understanding of and therapy for auditory hallucinations: A review of the literature and directions for further research. Clinical Psychology Review 2011;31:1313-23.

25. Hayward M, Awenat Y, McCarthy-Jones S, Paulik G, Berry K. Beyond beliefs: A qualitative study of people's opinions about their changing relations with their voices. Psychosis 2015;7(2):97-107.

26. Forster EM. Aspects of the Novel. First published London: Edward Arnold [1927]. London: Houghton Mifflin Harcourt, 1985.

27. Leech G, Short M. Style in Fiction: A Linguistic Introduction to English Fictional Prose. London: Longman, 1981.

28. Fowler R. Linguistic criticism. Oxford: Oxford University Press, 1986.

29. Culpeper J, Short M, Verdonk P, Eds. Exploring the Language of Drama: From Text to Context. London: Routledge, 1998.

30. Semino E, Short M. Corpus stylistics speech, writing and thought presentation in a corpus of English writing. London: Routledge, 2004.

31. Semino E. Pragmatic failure, mind style and characterisation in fiction about autism. Language and Literature 2014;23(2):141-58.

32. Demjén Z, Semino E. Henry's voices: The representation of auditory verbal hallucinations in an autobiographical narrative. Medical Humanities 2015;41(1):57-62.

33. Demjén Z, Marszalek A, Semino E, Varese F. "One gives bad compliments about me, and the other one is telling me to do things" - $(\mathrm{Im})$ Politeness and power in reported interactions between voice-hearers and their voices. In Demjén Z, ed. Applying Linguistics in IIIness and Healthcare Contexts. London: Bloomsbury, 2020.

34. Goffman E. Interaction Ritual: Essays on Face-to-face Interaction, Chicago: Aldine Publishing, 1967.

35. Brown P, Levinson SC Politeness: Some Universals in Language Use. Cambridge: Cambridge University Press, 1987.

36. Culpeper J. Impoliteness: Using Language to Cause Offence, Cambridge: Cambridge University Press, 2011.

37. Spencer-Oatey H. Managing Rapport in Talk: Using Rapport Sensitive Incidents to Explore the Motivational Concerns Underlying the Management of Relations. Journal of Pragmatics 2002;34(5):529-45. 
38. Spencer-Oatey $\mathrm{H}$. Theories of Identity and the Analysis of Face. Journal of Pragmatics 2007;39(4):639-56.

39. Spencer-Oatey H. Rapport management: A framework for analysis. In: Spencer-Oatey H, ed. Culturally Speaking: Culture, Communication and Politeness Theory. Second Edition. London: Continuum, 2008:11-47.

40. Simpson, P. Politeness phenomena in lonesco's The Lesson. In: Carter R, Simpson P, Eds. Language, Discourse and Literature: An Introductory Reader in Discourse Stylistics. London: Routledge, 1989:171-93.

41. Dynel M. Setting our house in order: The workings of impoliteness in multi-party film discourse. Journal of Politeness Research 2012;8:161-94.

42. Jones EE. Interpersonal Perception. New York: W.H. Freeman, 1990.

43. Luhrmann, T. M. (2017). Diversity within the psychotic continuum. Schizophrenia Bulletin, 43(1), 27-31.

44. Collins LC, Semino E, Demjén Z, Hardie A, Moseley P, Woods A, Alderson-Day B. A linguistic approach to the psychosis continuum: (dis)similarities and (dis)continuities in how clinical and non-clinical voice-hearers talk about their voices. Cogn Neuropsychiatry (under review).

\section{Acknowledgments}

We are grateful to Ben Alderson-Day, Peter Moseley and Angela Woods from the 'Hearing the Voice' project at Durham University for their generosity and feedback in the research that led to the production of this paper.

This research was supported by the Economic and Social Research Council, part of UK Research and Innovation (grant number: ES/R008906/1). 